\title{
TETRACHYRON OMISSUM Y TRIGONOSPERMUM ALEXANDRI, DOS ESPECIES NUEVAS DE COMPOSITAE-HELIANTHEAE DEL CENTRO DE MÉXICO*
}

\author{
Jerzy Rzedowski, Graciela Calderón de Rzedowski \\ y EMmanuel PÉREZ-CALIX \\ Instituto de Ecología, A.C., Centro Regional del Bajío, Apdo. postal 386, \\ 61600 Pátzcuaro, Michoacán, México.
}

\section{RESUMEN}

Se describen como nuevas e ilustran Tetrachyron omissum y Trigonospermum alexandri. La primera habita en el noreste de Querétaro y es próxima a T. websteri (Wussow \& Urbatsch) B. L. Turner. La segunda es una planta acuática o subacuática sólo conocida de un par de charcos cercanos a la población de Santa Clara del Cobre, en el norte de Michoacán. Posiblemente está emparentada con $T$. adenostemoides Less.

Palabras clave: México, Michoacán, Querétaro, Tetrachyron, Trigonospermum.

\begin{abstract}
Tetrachyron omissum and Trigonospermum alexandri are illustrated and described as new species. The first grows in northeastern Querétaro and is related to T. websteri (Wussow \& Urbatsch) B. L. Turner. The second is an aquatic or subaquatic plant known only from two pools in the vicinity of the town of Santa Clara del Cobre in northern Michoacán. It is possibly related to T. adenostemoides Less.
\end{abstract}

Key words: México, Michoacán, Querétaro, Tetrachyron, Trigonospermum.

\footnotetext{
* Trabajo realizado con apoyo económico del Instituto de Ecología, A.C. (cuenta 20006), del Consejo Nacional de Ciencia y Tecnología y de la Comisión Nacional para el Conocimiento y Uso de la Biodiversidad.
} 
En el transcurso de la preparación del fascículo de la Flora del Bajío y de regiones adyacentes, correspondiente a las Compositae-Heliantheae se encontraron algunas novedades, dos de las cuales se describen e ilustran a continuación.

Tetrachyron omissum Rzed. \& Calderón, sp. n. Fig. 1.

Frutex decumbens vel erectus usque $1 \mathrm{~m}$ altus; caulis striatus, brunneus, rubellus vel luteolus, glaber; folia opposita, elliptica vel anguste elliptica, usque 7.5 $\mathrm{cm}$ longa et $2.5 \mathrm{~cm}$ lata, minute serrulata vel fere integra, glabra; capitula plura terminalia subcorymbosa, pedunculis usque $3 \mathrm{~cm}$ longis, interdum leviter pubescentibus; flores omnes lutei, illi radii saepe 12, 10-12 mm longi, 2-3 mm lati, disci 45-60, corollis tubulosis ca. $3.5 \mathrm{~mm}$ longis; achaenia triquetra vel tetrangularia ca. $1.5 \mathrm{~mm}$ longa et $0.5 \mathrm{~mm}$ lata, pappus 4(5) squamis oblongis vel lanceolatis ca. $1 \mathrm{~mm}$ longis.

Arbusto decumbente a erecto, de (30)40 a 60(100) cm de alto; tallo estriado, glabro, café, rojizo o tendiendo a amarillento hacia la parte superior; peciolo hasta de $1.5 \mathrm{~cm}$ de largo, lámina foliar (a veces angostamente) elíptica, de 3 a $7.5 \mathrm{~cm}$ de largo y 1 a 2(2.5) cm de ancho, ápice por lo común agudo, en ocasiones obtuso, base cuneada, más o menos decurrente sobre el peciolo, margen variando de finamente serrulado a casi entero, asumiendo los dientecillos la forma de una glándula pequeña, a veces diminutamente ribeteado en el envés a algo revoluto, con la vena media y algunas laterales principales hundidas en el haz y prominentes en el envés, de textura coriácea, glabra en ambas caras; cabezuelas agrupadas por varias en conjuntos subcorimbosos en los extremos de las ramas, pedúnculos de (0.5)1 a $3 \mathrm{~cm}$ de largo, a veces algo pubescentes, sobre todo hacia la parte superior, donde suelen presentarse una a varias brácteas semejantes a las del involucro; éste turbinado, sus brácteas dispuestas en 2 a 3 series, oblongas a elípticas, las externas por lo común de color café oscuro, textura más dura y un poco más cortas y angostas que las internas que son amarillas, éstas de ca. $6 \mathrm{~mm}$ de largo y $1.5 \mathrm{a} 2 \mathrm{~mm}$ de ancho, receptáculo cilíndricocónico, páleas externas angostamente elípticas, cóncavo-convexas, amarillas, con frecuencia con tintes rojizos o cafés, de ca. $6 \mathrm{~mm}$ de largo y ca. $1.5 \mathrm{~mm}$ de ancho, las internas linear-lanceoladas, de ca. $5 \mathrm{~mm}$ de largo y 0.5 de ancho, planas; flores liguladas (8)12(16), sus láminas linear-oblongas a oblongo-elípticas, de (8)10 a 12 mm de largo, de (1.5)2 a 3(3.5) de ancho, con el ápice más bien redondeado, entero y a veces mucronado, o hendido a cortamente bi o tridentado, tubos de ca. $1 \mathrm{~mm}$ de largo, glabras; flores del disco 45 a 60, sus corolas de 3 a $3.5 \mathrm{~mm}$ de largo, amarillas cuando tiernas, tendiendo al café o morado al ir madurando, glabras; aquenios 




Fig. 1. Tetrachyron omissum Rzed. \& Calderón. A. rama con hojas y cabezuelas; B. flor ligulada con aquenio y vilano; C. flor del disco con estigmas salientes, aquenio y vilano. Ilustrado por Rogelio Cárdenas. 
triquetros o tetrangulares, de ca. $1.5 \mathrm{~mm}$ de largo y $0.5 \mathrm{~mm}$ de ancho, negruzcos, glabros, vilano de 4(5) escamas oblongas a lanceoladas, de ca. $1 \mathrm{~mm}$ de largo y ca. $0.2 \mathrm{~mm}$ de ancho, con frecuencia algo desiguales entre sí.

Tipo: México, Querétaro, El Llano Chiquito, municipio de Landa, S. Zamudio y E. Carranza 11167 (IEB).

Material adicional examinado: México, Querétaro: 9-10 km al sur de San Juan de los Durán, cerro Grande, municipio de Jalpan, B. Servín 110 (IEB); Las Abras del cerro Grande, al NE de Lagunita de San Diego, municipio de Landa, E. Carranza 2873 (IEB); extremo norte del Llano Chiquito, 2124'11" N, 9906'11" W, municipio de Landa, S. Zamudio et al. 11465 (IEB).

Habitante de áreas de relieve pronunciado dominado por rocas calizas con vegetación de encinares, de bosques de encino con coníferas, así como del bosque mesófilo de montaña, en altitudes entre 1900 y 2650 m. Localizado en floración de junio a octubre.

Aunque se registró varias veces como localmente abundante, Tetrachyron omissum parece representar un estrecho endemismo de un corto segmento de la Sierra Madre Oriental en la región limítrofe entre Querétaro y San Luis Potosí. Sólo se han visto especímenes de los municipios de Jalpan y Landa del primero de los estados, pero es muy probable su existencia también en el segundo.

Dado el carácter abrupto y escarpado de su habitat, así como su lejanía de la influencia de las poblaciones humanas, su supervivencia no se observa amenazada en forma directa.

La especie nueva está cercanamente relacionada con T. websteri (Wussow \& Urbatsch) B. L. Turner (T. orizabaense var. websteri Wussow \& Urbatsch), planta conocida de Tamaulipas, San Luis Potosí, Querétaro e Hidalgo. Inicialmente los ejemplares de la primera fueron identificados y distribuidos con el nombre Tetrachyron orizabaense Sch. Bip. ex Klatt y a esta particular circunstancia alude el epiteto omissum.

Ambas se encuentran en el noreste de Querétaro y prosperan en ambientes similares, pero no parecen convivir, pues $T$. websteri ocupa un área ubicada más al suroeste, concretamente en los municipios de Pinal de Amoles, San Joaquín y Cadereyta.

Las principales diferencias entre las dos especies en cuestión se resumen en el Cuadro 1. 
Cuadro 1. Principales diferencias entre Trigonospermum omissum y T. websteri.

T. omissum

Arbusto decumbente a erecto de $(0.3) 0.4$ a

$0.6(1) \mathrm{m}$ de alto

Tallo glabro

Lámina foliar (a veces angostamente) elíptica, de 3 a $7.5 \mathrm{~cm}$ de largo y 1 a 2 (2.5) cm de ancho, glabra

Vilano de 4(5) escamas oblongas a lanceoladas, con frecuencia ligeramente desiguales entre sí
T. websteri

Arbusto erecto, de (0.5)1 a 2(3) m de alto

Tallo levemente pubescente hacia la porción superior

Lámina foliar más o menos ampliamente elíptica, de (3)5 a 15(17) cm de largo y (1) 1.5 a 5(7) $\mathrm{cm}$ de ancho, pubescente sobre las nervaduras en el envés.

Vilano de 4 a 5(10) escamas lineares a subuladas, acompañadas con frecuencia de varias otras diminutas intercaladas

Trigonospermum alexandri Rzed., Calderón \& Pérez-Calix sp. n. Fig. 2.

Planta annua aquatica vel subaquatica erecta vel ascendens ad $80 \mathrm{~cm}$ alta; caules fistulosi saepe proximaliter radicantes, dense hirsuto-pilosi pilis pluricellulosis ad $2 \mathrm{~mm}$ longis et breviter glanduloso-puberuli; folia supera sessilia, cetera bases petiolares ad $1.5 \mathrm{~cm}$ longas et $4 \mathrm{~mm}$ latas ferentia, laminis plerumque ovalis (2)3-5(6) cm longis, (0.8)1.5-3.5 cm latis, apice acutis vel acuminatis triplinervatis utrinque pilosis; capitula aggregata in catervis paniculiformibus dichotomis foliosis, juventute subglomerata; involucri bracteae externae 3(4) patentes vel reflexae plerumque lineares 2-3 mm longae, internae (4)5(6) plerumque ellipticae ca. $3 \mathrm{~mm}$ longae pilosae et breviter glanduloso-puberulae, achaenia amplectentes; flores radii (4)5(6) laminis ca. $1.5 \mathrm{~mm}$ longis, ca. $2 \mathrm{~mm}$ latis, trilobatis, eburneis; flores disci plerumque 6 , velut staminati fungentes, corollis infundibuliformibus eburneis ca. 2 $\mathrm{mm}$ longis; achaenia obpyramidata trigona, $2-2.5 \mathrm{~mm}$ longa, nigra, striata, nitida.

Planta herbácea anual, acuática emergente o subacuática, erecta o ascendente, hasta de $80 \mathrm{~cm}$ de alto; tallo fistuloso, hasta de $6 \mathrm{~mm}$ de diámetro, simple o ramificado en la porción superior pero a menudo radicante en los nudos inferiores, densamente hirsuto-piloso con pelos multicelulares hasta de $2 \mathrm{~mm}$ de largo, acom- 


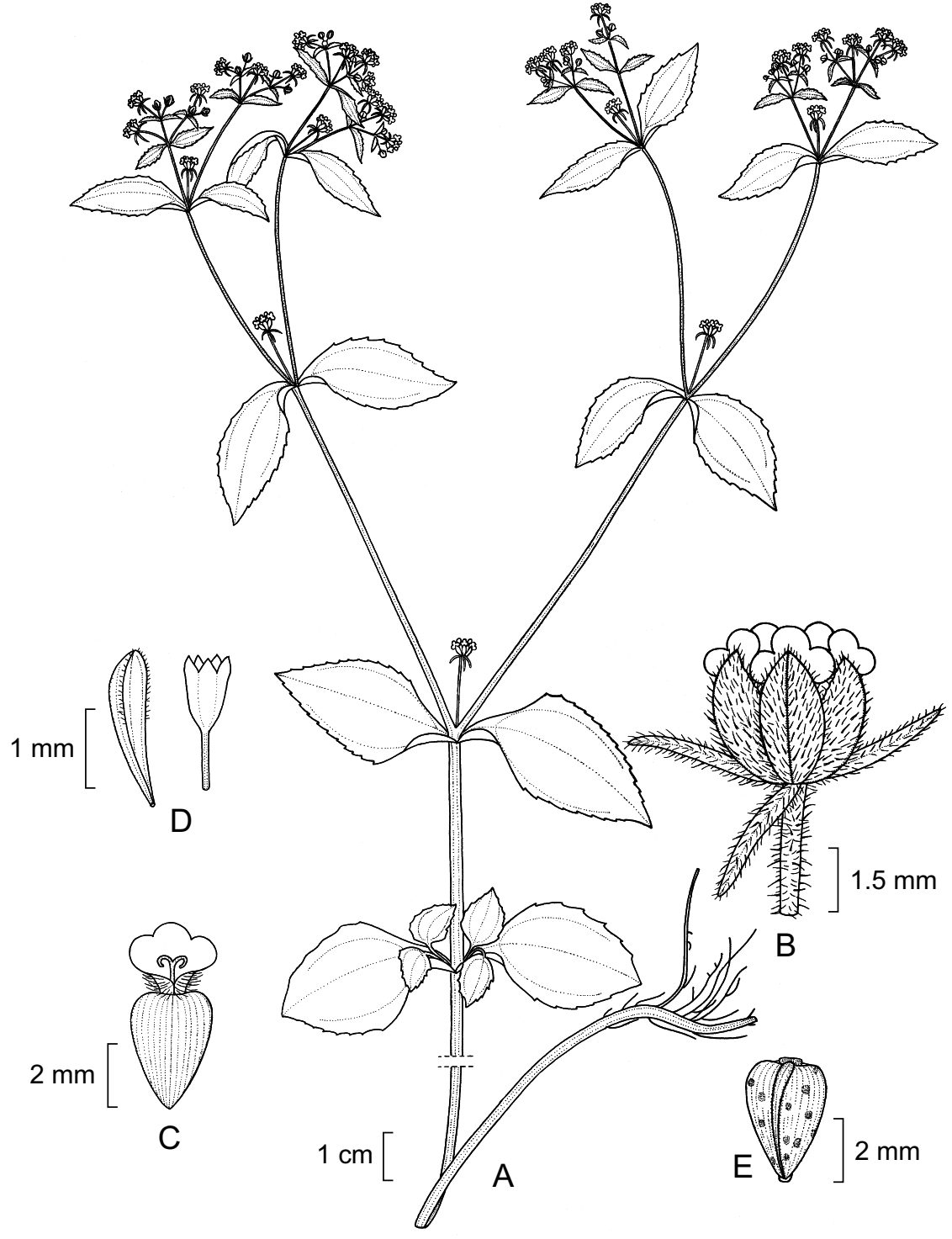

Fig. 2. Trigonospermum alexandri Rzed., Calderón \& Pérez-Calix. A. aspecto general de la planta; B. cabezuela; C. flor ligulada femenina; D. corola de la flor masculina del disco y pálea adyacente; E. aquenio. Ilustrado por Rogelio Cárdenas. 
pañados de pelos glandulosos más cortos; hojas opuestas, las superiores sésiles, las restantes con bases peciolares hasta de $1.5(2) \mathrm{cm}$ de largo y $4(8) \mathrm{mm}$ de ancho, con frecuencia dobladas sobre sí mismas especialmente hacia el extremo proximal, lámina ovada a lanceolada o elíptica, de (2)3 a 5(6) cm de largo y de (0.8)1.5 a $3.5 \mathrm{~cm}$ de ancho, ápice agudo a acuminado, base cuneada a redondeada, margen regular a irregularmente serrado, triplinervada, de textura membranácea, verde oscura en el haz, más pálida en el envés, pilosa con pelos hasta de $1 \mathrm{~mm}$ de largo en ambas superficies; cabezuelas agrupadas en los extremos de las ramas en forma de panículas cimosas, dicotómicas y foliosas, pero por lo general en su juventud con pedúnculos de menos de $5 \mathrm{~mm}$ de largo, de manera que a menudo los conjuntos de cabezuelas jóvenes aparentan especie de glomérulos, pedúnculos filiformes, en la madurez hasta de 2.5(3) cm de largo; involucro campanulado, sus brácteas dispuestas en dos series desiguales, las exteriores 3(4) patentes o reflejas, lineares o linear-lanceoladas, de 2 a $3 \mathrm{~mm}$ de largo, las interiores (4)5(6), obovadas a suborbiculares o elípticas, de ca. $3 \mathrm{~mm}$ de largo, agudas en el ápice, pilosas y cortamente glanduloso-pubérulas por fuera, abrazando los aquenios de las flores periféricas, receptáculo convexo, diminuto, páleas externas oblanceolado-obovadas, las interiores linear-oblanceoladas, todas glabras o algo pubérulas en el ápice, de ca. $2 \mathrm{~mm}$ de largo; flores liguladas (4)5(6), sus tubos de menos de $0.5 \mathrm{~mm}$ de largo, muy densamente vilosos, sus láminas anchamente deltoides en contorno general, trilobadas, de ca. $1.5 \mathrm{~mm}$ de largo y ca. $2 \mathrm{~mm}$ de ancho, blanquecinas o de color crema, glabras, papilosas por dentro; flores del disco por lo general 6, sus corolas pentámeras o a veces tetrámeras, infundibuliformes, de color crema, glabras, de ca. $2 \mathrm{~mm}$ de largo, de los cuales aproximadamente la mitad pertenece a un tubo angosto y la otra porción a una garganta turbinada y a los 5 lóbulos, anteras de poco menos de $1 \mathrm{~mm}$ de largo, de color blanquecino a café, ovario diminuto, estéril, a menudo en forma de estípite en la madurez de la cabezuela; aquenios obpiramidales, trígonos, de 2 a $2.5 \mathrm{~mm}$ de largo, negruzcos, con frecuencia moteados con puntos más oscuros, estriados, glabros, brillantes, sin vilano.

Tipo: México, Michoacán, NW de Santa Clara del Cobre, municipio de Santa Clara del Cobre, lugar cenagoso, alt. 2200 m, 18.VIII.1995, E. Pérez-Calix y T. Platas 3169 (IEB), isotipos por distribuirse.

Material adicional examinado: México, Michoacán, NW de Santa Clara del Cobre, municipio de Santa Clara del Cobre, pradera encharcada, alt. $2150 \mathrm{~m}$, 22.IX.1989, E. Pérez-Calix 673 (IEB). 
Trigonospermum alexandri es una planta acuática o subacuática, hasta ahora sólo encontrada en lugares temporalmente inundados en los alrededores de la población de Santa Clara del Cobre, también conocida como Villa Salvador Escalante, en el norte de Michoacán.

Los charcos en cuestión están rodeados por terrenos de aprovechamiento agrícola y en la época seca del año se encuentran sometidos al libre pastoreo del ganado. Dadas estas circunstancias, así como al reducido tamaño de las poblaciones de T. alexandri, la especie califica como altamente vulnerable a la extinción.

El taxon nuevo difiere de las demás especies conocidas de Trigonospermum en ser planta acuática o subacuática con tallos fistulosos y radicantes, en sus hojas con las bases pecioliformes muy anchas, en su inflorescencia organizada a manera de conjunto paniculiforme folioso, así como en la forma de las corolas de las flores liguladas.

En sus cabezuelas, así como en sus flores liguladas diminutas y de color crema, al igual que en sus aquenios obpiramidales, de 2 a $2.5 \mathrm{~mm}$ de largo, T. alexandri se asemeja y posiblemente está emparentado con T. adenostemoides Less., planta conocida de Veracruz y Chiapas.

El nombre del nuevo taxon se dedica a la memoria del recientemente desaparecido botánico mexicano Alejandro Novelo Retana, quien fue un trascendente y apasionado estudioso de las plantas acuáticas de nuestro país y de otras partes de Latinoamérica. 